\title{
NILAI DAN UNSUR BUDAYA PADA CERITA RAKYAT BUAH UDAK SUKU DAYAK LINOH
}

\section{VALUE AND CULTURAL ELEMENT IN BUAH UDAK FOLKLORE DAYAK LINOH ETHIC GROUP}

\author{
Yusuf Olang1, Ursula Dwi Oktaviani $^{2 *}$, Yati Oktaviani ${ }^{3}$ \\ Pendidikan Bahasa dan Sastra Indonesia, STKIP Persada Khatulistiwa Sintang, \\ Indonesia ${ }^{1,2,3}$ \\ yusufolang@gmail.com ${ }^{1}$, ursuladwioktaviani@gmail.com ${ }^{2}$, \\ yatioktaviani@gmail.com ${ }^{3}$ \\ *penulis korespondensi
}

\begin{tabular}{ll}
\hline Info Artikel & ABSTRAK \\
\hline Sejarah artikel: & Tujuan penelitian ini adalah mendeskripsikan nilai dan unsur budaya pada \\
Diterima: & sastra lisan cerita rakyat suku Dayak Linoh. Penelitian ini menggunakan \\
5 Juli 2021 & metode deksriptif kualitatif. Data pada penelitian ini adalah semua kutipan- \\
Direvisi: & kutipan yang terdapat dalam cerita rakyat suku Dayak Linoh. Sumber data \\
8 Juli 2021 & dalam penelitian ini adalah cerita rakyat suku Dayak Linoh dari Kecamatan \\
Disetujui: & Sungai Tebelian Kabupaten Sintang yang berisi satu cerita rakyat Dayak \\
20 Juli 2021 & Linoh yang berjudul Buah Udak. Hasil analisis data menunjukkan nilai \\
& budaya yang menggambarkan hubungan manusia dengan Tuhan, hubungan \\
Kata kunci: & manusia dengan alam, hubungan manusia dengan masyarakat, hubungan \\
nilai budaya, cerita & manusia dengan orang lain atau sesamanya, hubungan manusia dengan \\
rakyat, Dayak Linoh & dirinya sendiri. Sedangkan unsur budaya terdapat: peralatan dan \\
& perlengkapan hidup, sistem kekerabatan dan organisasi sosial, bahasa, \\
& kesenian, sistem kepercayaan, dan sistem ilmu dan pengetahuan. \\
& Masyarakat Dayak Linoh memercayai nilai budaya yang terdapat dalam \\
& cerita tersebut dan menjadiadat istiadat/tradisi.
\end{tabular}

\begin{tabular}{|c|c|}
\hline Article Info & ABSTRACT \\
\hline $\begin{array}{l}\text { Article history: } \\
\text { Received: } \\
\text { 5 July } 2021 \\
\text { Revised: } \\
\text { 8 July } 2021 \\
\text { Accepted: } \\
\text { 20 July } 2021 \\
\\
\text { Keyword: } \\
\text { cultural value, folklore, } \\
\text { Dayak Linoh. }\end{array}$ & $\begin{array}{l}\text { The purpose of this study was to describe the values and cultural elements } \\
\text { in the oral literature of the Linoh Dayak folklore. This study uses a } \\
\text { qualitative descriptive method. The data in this study are all quotes } \\
\text { contained in the folklore of the Linoh Dayak group ethic. The source of the } \\
\text { data in this study is the folklore of the Dayak Linoh group ethic from Sungai } \\
\text { Tebelian District, Sintang Regency which contains a Dayak Linoh folktale } \\
\text { entitled Buah Udak. The results of data analysis show cultural values that } \\
\text { describe the relationship between humans and God, human relationships } \\
\text { with nature, human relationships with society, human relationships with } \\
\text { other people or with each other, human relationships with themselves. While } \\
\text { the elements of culture are: tools and equipment for life, kinship systems } \\
\text { and social organization, language, arts, belief systems, and systems of } \\
\text { science and knowledge. The Linoh Dayak community believes in the } \\
\text { cultural values contained in the story and becomes a custom/tradition. }\end{array}$ \\
\hline
\end{tabular}

Copyright $\odot$ 2021, Stilistika: Jurnal Pendidikan Bahasa dan Sastra DOI: http://dx.doi.org/10.30651/st.v14i2.8917 


\section{PENDAHULUAN}

Nilai budaya merupakan akar atau jiwa dari kebudayaan yang dimiliki oleh masyarakat. Tata hidup yang tampak dalam masyarakat adalah cerminan nilai budaya yang terkandung di dalamnya. Nilai budaya juga dijadikan dasar suatu konsep dan dasar saat berkomunikasi dengan masyarakat lainnya. Nilai budaya adalah tingkatan yang paling absrak dari adat istiadat,hidup, dan alam pikiran masyarakat. Yang dapat diungkapkan melalui pengamatan pada gejala-gejala yang lebih nyata seperti tingkah laku, benda-benda material sebagai hasil dari penuangan konsep-konsei melalui tindakan berpola. Menurut ( Putri \& Nugraha, 2017) "nilai-nilai budaya yang tinggi dapat dimanfaatkan bagi masyarakat umum, sedangkan bagi sejarah sastra lama akan dicatat bahwa sastra pada masa itu telah berisi nilai budaya yang berguna dalam kehidupan masyarakat atau dapat dijadikan teladan". Dalam kaitan itu sistem nilai budaya merupakan sejumlah pandangan mengenai soal-soal yang paling berharga dan bernilai dalam hidup. Sistem nilai budaya menjiwai semua pedoman yang mengatur tingkah laku warga pendukung kebudayaan yang bersangkutan. Selain itu juga, nilai budaya merupakan konsep-konsep mengenai sesuatu yang ada dalam alam pikiran sebagian besar dari masyarakat yang dianggapnya bernilai, berharga, penting dalam melalui keteladanan bersama, dan mendorong suatu pembangunan spiritual, seperti tahan menderita, berusaha dan bekerja keras, toleransi terhadap pendirian atau kepercayaan orang lain, dan gotongroyong.

Kebudayan terdiri atas tujuh unsur yang saling berkaitan, yaitu sistem kemasyarakatan dan organisasi sosial, sistem pengetahuan, sistem peralatan hidup dan teknologi, sistem mata pencaharian hidup, kesenian, serta sistem bahasa (Koentjaraningrat, 1994). Selanjutnya Siregar dalam (Indrastuti, 2018) memaparkan bahwa kebudayaan menjadi acuan kuat untuk melihat tata cara hidup manusia dan hal tersebut juga berhubungan dengan kepercayaan, sikap, serta produk khas yang dihasilkan oleh manusia sebagai suatu kelompok tertentu.

Menurut (Gumilar \& Sulasman, 2013) "setiap unsur kebudayaan tidak bersifat statis, tetapi akan berubah sesuai dengan tingkat kebutuhan dan proses adapttif yang diperlukan sebab kebudayaan berfungsi mempermudah kehidupan manusia.". Kebudayaan merupakan sesuatu yang menembus dan mempengaruhi setiap aspek kehidupan, namun tidak statis, dia merupakan proses atau keadaan yang terus-menerus berubah dan beradaptasi terhadap konteks baru, tuntutan, dan kebutuhan baru (Liliweri, 2014). Selanjutnya (Zakiyah \& Rusdiana, 2014) mengartikan budaya sebagai seluruh sistem berpikir, nilai, moral, norma, dan keyakinan manusia yang dihasilkan masyarakat".

Cerita rakyat dapat diartikan sebagai ekspresi budaya suatu masyarakat melalui tutur bahasa yang berhubungan langsung dengan berbagai aspek budaya dan susunan nilai sosial masyarakat tersebut. Dahulu, cerita rakyat diwariskan secara turunmenurun dari satu generasi ke generasi berikutnya secara lisan (Hutomo, 1991). Selanjutnya menurut (Sahril, 2013) "cerita rakyat adalah gambaran otentitas masyarakat yang mencerminkan perilaku dan budaya masyarakat setempat.

Cerita Rakyat merupakan salah satu satra lisan satu unsur kebudayaan 
daerah yang sangat penting untuk tetap dilestarikan, agar selalu menjadi ungkapan budaya bagi masyarakat. Indonesia merupakan negara kepulauan yang terbesar, dari masing-masing pulau tersebut memiliki cerita rakyat atau sastra lisan yang berbeda-beda, dan salah satunya adalah pulau Kalimantan Barat, yang hampir semua penduduk aslinya ialah suku Dayak. Suku Dayak di Kalimantan Barat banyak berbagai suku, salah satunya ialah suku Dayak Linoh. Menurut (Choirudin, 2018) "Sastra daerah merupakan salah satu bentuk dari sastra lisan yang sudah ada dari zaman dahulu dan terus berkembang hingga saat ini". Tradisi lisan ialah salah satu bentuk seni sastra atau pegguanaan bahasa yang dituturkan dan diwariskan atau diekspresikan dalam bentuk teks-teks lisan.

Pokok permasalahan ialah penuturan cerita rakyat secara tradisional semakin jarang dilakukan. Hal tersebut mengakibatkan banyaknya penutur yang lupa akan cerita rakyat sudah didengar. Kebiasaan orang tua mewariskan cerita rakyat pada anakanaknya dengan cara mendongeng sebelum tidur semakin jarang dilakukan karena adanya komik, CD, dan sebagainya yang semakin modern.

Melihat keadaan demikian, penelitian yang akan melihat nilai budaya pada cerita rakya suku Dayak Linoh pada cerita rakyat Buah Udak, dan beberapa cerita lainnya. Buah udak merupakan seorang gadis di dalam buah udak, lalu gadis itu tidak sengaja bertemu seorang pria biasa yang menjadi suaminya, setelah itu mereka memutuskan untuk hidup bersama, dan kemudian mereka memiliki anak. Anaknya bertanya tentang ibunya kepada neneknya. Neneknya menceritakan tentang ibunya kepada cucunya. Cucunya pun bertanya kepada ibunya, apakah benar cerita yang telah diceritakan neneknya tentang ibunya. Ibunya menjawab benar apa yang dikatakan neneknya. Lalu gadis itu berpikir bahwa mereka tidak ingin melihanya lagi dan merasa kecewa. Setelah itu ia pergi sehabis menidurkan anaknya, dan kembali menjadi buah udak lagi.

Peneliti berharap agar bisa mengembangkan dan mendorong untuk masyarakat setempat supaya dapat melestarikan dan menjaga cerita rakyat di daerahnya agar tetap terjaga, dan selalu tertanamkan dalam masyarakat atau untuk membangkitkan kembali minat generasi muda dalam mendengarkan cerita rakyat. Mengembangkan kembali cerita rakyat dalam bentuk lisan maupun tulisan. Agar kita dan generasi selanjutnya dapat mengenal secara lebih dalam tentang cerita rakyat dan nilai pada cerita rakyat, dan tetap tumbuh dan berkembang di kalangan masyarakat maupun kalangan muda.

\section{METODE}

Metode yang digunakan pada penelitian ini adalah deskriptif dan pendekatan kulitatif, yaitu merupakan gambaran atau mendeskripsikan secara sistematis, faktual, dan akurat.

Data pada penelitian ini adalah semua kutipan-kutipan yang terdapat dalam cerita rakyat suku Dayak Linoh. Sumber data dalam penelitian ini adalah cerita rakyat suku Dayak Linoh dari Kecamatan Sungai Tebelian Kabupaten Sintang, yang berisi satu cerita rakyat Dayak Linoh, yaitu Buah Udak. Instrumen utama pada penelitian ini adalah informan dengan alat bantu yang digunakan untuk mengumpulkan data yang berupa rekaman dari hasil yang diceritakan oleh informan yang 
merupakan tetua atau yang dipercaya tahu dan mengerti seluk beluk di suku Dayak Linoh. Data yang akan dianalisis dalam penelitian ini akan ditranskripsikan melalui aplikasi elan yang membantu memudahkan peneliti dalam melakukan analisi data.

Teknik pengumpul data pada penelitian ini yakni teknik dokumentasi, wawancara tak berstruktur, dan teknik rekam. Alat pengumpul data pada penelitian ini yakni dokumen, lembar wawancara dan alat rekam.

Teknik analisis data pada penelitian ini yakni 1) mentranskripsikan hasil ujaran dengan aplikasi elan yang telah direkam ke dalam bahasa tulis dan diedit ke word. 2) setelah ditranskripsikan, peneliti menterjemahkan dari bahasa Dayak Linoh ke dalam bahasa Indonesia, dan dibantu oleh Bapak Idin (salah satu tetua di suku Dayak Linoh) dalam menterjemahkannya.

mengklasifikasikan hasil penelitian yang sudah diterjemahkan berdasarkan sub masalah.

\section{HASIL DAN PEMBAHASAN}

Hasil analisis data pada cerita Buah Udak yaitu nilai budaya dan unsur budaya, hal ini dapat dilihat pada pembahasan berikut.

\section{Analisis Nilai Budaya Pada Cerita Rakyat}

Nilai budaya yang ditemukan dalam cerita yang dianalisis adalah (1) nilai budaya dalam hubungan manusia dengan Tuhan, (2) nilai budaya dalam hubungan manusia dengan alam, (3) nilai budaya dalam hubungan manusia dengan masyarakat, (4) nilai budaya dalam hubunga manusia dengan orang lain atau sesamanya, dan (5) nilai budaya dalam hubungan manusia dengan dirinya sendiri.
1. Nilai Budaya dalam Hubungan Manusia dengan Tuhan

Nilai-nilai budaya yang muncul dalam hubungann manusia dengan Tuhan adalah nilai keimanan atau kepercayaan kepada Tuhan, dan nilai berserah diri, yang menggambarkan hubungan manusia (Sugiyono, 2015) dengan Tuhan mempunyai wujud manusia yang taat pada perintah Tuhan, yaitu pada cerita rakyat Buah Udak.

Mereka bersyukur kepada Yang Maha Kuasa karena telah mempersatukan mereka.

Kutipan di atas menyatakan bahwa mereka bersyukur kepada Yang Maha Kuasa karena telah dipersatukan dan dipertemukan. Yang Maha Kuasa tersebut akan membantu manusia dapat berbentuk nyata, berupa binatang yang akan menolong ataupun berupa benda yang dapat menyelamatkan manusia, dan mereka tetap bersyukur atas pertolongannya. Menggambarkan kehidupan masyarakat masa itu yang masih memiliki kepercayaan kepada sang pencipta bahwa dapat membantu menyelesaikan masalah yang dihadapi, yang bisa kita pelajari dan kita terapkan dalam kehidupan kita saat ini.

2. Nilai Budaya dalam Hubungan Manusia dengan Alam

Nilai budaya yang muncul dalam hubungan manusia dengan alam merupakan nilai pemanfaatan daya alam. Nilai budaya memiliki tiga wujud, yaitu alam menyediakan kebutuhan hidup manusia, manusia memelihara alam dengan berkesinambungan, alam menjadi 
saksi hidup perbuatan manusia. Wujud sangat yang tampak bahwa hubungan manusia dengan alam tercermin pada cerita Buah Udak, yaitu sebagai berikut.

Tidak lama kemudian, berangkatlah Kolin mencari buah udak itu, jadi dihampirinya kelandang dan melihatnya bergulingguling "Wihh ih" kata si Kolin "cantik dan dia seperti manusia" sahutnya lagi dan dipegangnya buah udak itu.

Kutipan di atas bahwa Kolin pergi mencari buah udak itu keladang dengan menanyai mamaknya, sampai dia melihat bahwa buah udak itu serupa dengan manusia dan dilihat buah udak itu sangat cantik, sampai Kolin terpikat kecantikanya. Cerita di atas menggambarkan alam yang menjadi saksi perbuatan manusia karena buah udak bisa berubah menjadi manusia.

Wujud sangat yang tampak bahwa hubungan manusia dengan alam tercermin pada cerita Buah Udak, yaitu sebagai berikut.

Mereka bersyukur kepada yang Maha Kuasa karena telah mempersatukan mereka. Mereka juga tetap menjaga alam sekitar dengan merawat alam sekitarnya agar tetap indah.

Kutipan di atas menyatakan bahwa mereka tetap menjaga keindahan alam sekitar dan merawatnya agar tetap terjaga keindahannya dan kelarasannya agar tidak terganggu. Kehidupan yang diberikan oleh Tuhan seharusnya disyukuri dan saling toleransi tanpa memandang status sosial atau status ekonomi karena di mata Sang Pencipta semua manusia itu sederajat.

3. Nilai Budaya dalam Hubungan Manusia dengan Masyarakat

Nilai budaya yang muncul dalam hubungan manusia dengan masyarakat merupakan nilai musyawarah, cinta tanah air, dan kepatuhan pada adat. Wujud sangat yang tampak bahwa hubungan manusia dengan masyarakat tercermin pada cerita Buah Udak, yaitu sebagai berikut.

Setelah mereka sudah selesai memasak dan memulai acara pestanya mereka memanggil semua warga untuk menyantap makan yang sudah disiapkan, mereka berdua duduk menikah mereka. Lalu, mereka sengkelan colek kiri, colek kanan. Setelah selasai acara pestanya mereka berdua sudah resmi menjadi pasangan.

Kutipan di atas menceritakan bahwa Kolin menikah dan masih tetap menjaga adat istidat dengan mengadakan acara nikah adat, yaitu mereka bersengkelan (sambil) colek kiri, colek kanan. Dengan mempertahankan adat mereka melaksanakan segala persiapan dan keberlangsungannya acara adat tersebut tampat terhambat, sampai 
mereka dua sah menjadi pasangan suami istri setelah selasai acara adat tersebut. Cerita di atas menggambarkan bahwa mereka masih patuh dengan adat dalam suatu daerah maupun masyarakat sekitar.

4. Nilai Budaya dalam Hubunga Manusia dengan Orang Lain/Sesamanya

Nilai budaya yang menonjol dalam hubungan manusia dengan manusia lain merupakan suka menolong, toleransi, suka memaafkan, kasih sayang balas budi, kepatuhan, dan kesetiaan. Manusia pada hakekatnya ingin hidup damai dalam komunitas yang harmonis. Wujud sangat yang tampak bahwa alam menyediakan kebutuhan hidup bagi manusia tercermin pada cerita Buah Udak adalah sebagai berikut.

Tidak lama kemudian, mereka mengadakan pesta, Kolin sangat senang. Setelah itu, mereka mengadakan pesta dan Kolin berkata "Wahh sangat cantik" dia berkata kepada Mia Udak, "itulah bagus" kata si mamaknya. Lalu mereka memanggil warga-warga untuk pesta pernikahan. Mereka membunuh sapi, kerbau, ayam, untuk hidangan dalam acara pesta yang mereka adakan. Setelah mereka sudah selesai memasak dan memulai acara pestanya mereka memanggil semua warga untuk menyantap makan yang sudah disiapkan, mereka berdua duduk menikah mereka. Lalu, mereka sengkelan colek kiri, colek kanan.

Kutipan di atas menunjukkan bahwa Kolin dan mamaknya ingin mempereratkan tali kebersamaan terhadap masyarakat agar mereka tetap harmonis dan damai tentram dalam lingkungan, seperti mereka mengundang masyarakat sekitar dalam acara pernikan mereka. Masyarakat sekitar juga menghadiri pesta itu dan sambil menyantapi hidangan yang telah disediakan oleh Kolin sekeluarga. Dengan acara pernikahan tersebut mereka menjalin tali persaudaraan dengan kehamonisan dalam lingkungan masyarakat setempat. Dalam cerita tersebut menggambarkan bahwa mereka memiliki hubungan cinta kasih dan suka menolong. Karena dalam cerita tersebut memanggil warga masyarakat untuk menghadiri acara pernikahan Kolin dan Mia Udak.

5. Nilai Budaya dalam Hubungan Manusia dengan Dirinya Sendiri

Nilai budaya yang menonjol dalam hubungan manusia dengan diri sendiri merupakan nilai tanggungjawab, dan nilai keberanian. Wujud sangat yang tampak bahwa nilai budaya dalam hubungan manusia dengan diri sendiri tercermin pada cerita Buah Udak, yaitu sebagai berikut.

Setelah itu dia menidurkan anaknya dan mengayun-ayun anaknya sambil berkata, "Kamu sudah tidak mau lihat aku lagi", waktu dia sudah menidurkan anaknya, dan sambil diayunayun sampai anaknya tidur. lalu dia melantunkan sebuah syair 
katanya "Jadi gelang hari panas aku layu, hari hujan aku mekar". Setelah melantnkan syair itu, tubuhnya menjadi daun yang berbulu, lalu tumbuh ke tumbuh, tumbuh ke tumbuh, lalu dia melantunkan syair lagi "Aka aka noli golang kalau panas aku layu, kalau huajan aku mekar". Lalu badannya habis tumbuh daun yang berbulu, dan dia bergulingguling menjadi buah udak lagi. Setelah itu ditambal Kolin segala lantai, dinding yang bolong, untuk istrinya keluaroleh istrinya, dan kisahnya sudah selesai serta dia menjadi buah udak kembali.

Pada kutipan di atas, Mia Udak tetap pada pendiriannya dan berani menggambil keputusan atas kejadian yang telah terjadi. Walaupun dengan kecewa dia tetap memutuskan untuk kembali kekayangan dengan kesedihan yang dia alami, dia juga tetap bertanggung jawab kepada anaknya sebelum Mia udak kembali kekayangan dengan menidurkan anaknya sampai pulas. Dia tetap teguh dengan pendiriannya, berani, dan bertanggung jawab atas kejadian yang telah terjadi tanpa berpikir kembali matang-matang.

\section{Analisis Unsur Budaya pada Cerita Rakyat}

Unsur budaya yang ditemukan pada cerita rakyat yang dianalisis adalah (1) peralatan dan perlengkapan hidup (teknologi), (2) sistem kekerabatan dan organisasi sosial, (3) bahasa, (4) kesenian, (5) sistem kepercayaan (religi), dan (6) sistem ilmu dan pengetahuan
1. Peralatan dan Perlengkapan Hidup (Teknologi)

Peralatan dan perlengkapan hidup (teknologi) adalah salah satu komponen kebudayaan, yaitu menyangkut cara-cara atau teknik memproduksi, memakai, serta memelihara segala peralatan dan perlengkapan. Teknologi muncul dalam cara-cara manusia mengorganisasikan masyarakat dan mengkspresikan rasa keindahan, atau memproduksi hasil-hasil kesenian. Sistem ini tergambarkan pada cerita rakyat Buah Udak, yaitu sebagai berikut.

Sedangkan Kolin bekerja sebagai penepuh segala pisau, parang, dan lain-lainya yang bisa untuk dijualkan.

Kutipan di atas menjelaskan bahwa keadaan masyarakat yang masih sederhana. Walau dengan keterbatasan bahan dan alat yang mereka miliki, masyarakat mampu membuat sesuatu yang bisa memudahkan kehidupan yang mereka jalani. Akal pikiran manusia digunakan untuk menciptakan dan membuat sesuatu yang biasa menjadi baru demi mempertahankan hidup, dan dapat memenuhi kebutuhan mereka sehari.

\section{Sistem Kekerabatan dan Organisasi} Sosial

Kekerabatan adalah unit-unit sosial sosial yang terdiri atas beberapa keluarga yang memiliki hubunga darah atau hubungan perkawinan. Sedangkan organisasi sosial adalah perkumpula sosial yag dibentuk oleh masyarakat, baik yang berbadan hukum, yang berfungsi sebagai sarana partisipasi 
masyarakat dalam pembangunan bangsa dan negara. Sistem kekerabatan ini terdapat pada beberapa cerita rakyat Buah Udak, yaitu sebagai berikut.

Lalu, "mengapa mama buang buah udak itu, coba diambi" kata si Kolin "Ahhh" kata mamaknya dan Kolin bertanya" dimana mamak menggalinya tadi" mamaknya menjawab dan berkata "diladang kita itulah, dan carilah bekas tempat aku menggali buah udak itu". Tidak lama kemudian, berangkatlah Kolin mencari buah udak itu, jadi dihampirinya kelandang.

Kutipan diatas menyatakan bahwa pada cerita rakyat Buah Udak terkandung unsur budaya saling membantu dalam masalah berladang. Hal tersebut tergambar pada kehidupan masyarakat yang harmonis, berdampingan selalu saling membantu, dan masyarakat saling membantu dan bergotong royong dalam menyelesaikan sesuatu. Karena Masyarakat pada umumnya berkerja sama, serta bergotong royong agar memudahkan manusia dalam memenuhi tujuan yang akan dicapai bersama serta menjalin rasa kebersamaan dan kekeluargaan yang lebih erat, dan harmonis antar masyarakat.

\section{Bahasa}

Bahasa merupakan alat atau perwujudan budaya yang digunakan manusia untuk saling berkomunikasi atau berhubungan, baik melalui tulisan, lisan, maupun gerakan atau bahasa isyarat, dengan tujuan menyampaikan maksud kepada lawan bicara atau orang lain. Melalui bahasa, manusia dapat menyesuaikan diri dengan adat istiadat, tingkah laku, tata krama, dan sekaligus mudah membaurkan diri dengan masyarakat. Sistem bahasa ini tampak dalam cerita rakyat Buah Udak, yaitu sebagai berikut.

Jadi, anaknya terus menanggis, "mengapa kamu menanggis bah abang, makan sudah makan" kata si Mia Udak kepada anaknya. Mungkin dia memanggil neneknya tadi kata Mia Udak, dan anaknya memanggil neneknya "sini nek" katanya, dan pergilah neneknya menemui cucunya "mandi nek" kata cucunya."

Kutipan di atas menyatakan bahwa adanya sistem bahasa menggunakan bahasa daerah dan bahasa sehari-hari mereka gunakan. Kutipan di atas dapat ditarik sebuah kesimpulan bahwa bahasa yang digunakan oleh masyarakat. Bahasa daerah pada kutipan tersebut hanya dipahami dan dimengerti oleh penutur aslinya saja, bahkan bahasa ini juga digunakan oleh sesama penutur bahasa daerah ini saja.

\section{Kesenian}

Kesenian mengacu pada nilai keindahan yang berasal dari eksperesi hasrat manusia terhadap keindahan. Setelah memenuhi kebutuhan fisik manusia juga memerlukan sesuatu yang dapat memenuhi kebutuhan psikis mereka, sehingga lahirlah sebuah kesenian atau karya seni. Sistem kesenian ini 
tergambar pula pada cerita rakyat Buah Udak, yaitu sebagai berikut.

Lalu dia melantunkan syair lagi "Aka aka noli golang kalau panas aku layu, kalau huajan aku mekar".

Kutipan di atas menyatakan bahwa cerita rakyat tersebut terdakat adanya kesenia, karena Mia Udak melantukan sebuah syair perpisahan kerena dia akan kemabali menjadi buah udak. Dari kutipan di atas, dapat disimpulkan bahwa masyarakat memiliki berbagai kesenian yang sering mereka gunakan dalam setiap kegiatan, dan lain-lain.

\section{Sistem Kepercayaan (Religi)}

Sistem kepercayaan merupakan adanya penguasa tertinggi dari sistem jagat raya, yang juaga mengendalikan manusia sebagai salah satu bagian jagat raya. Agama dan sistem kepercayaan lainnya sering terintegrasi dengan kebudayaan. Sistem religi ini terdapat pada cerita rakyat Buah Udak, yaitu sebagai berikut.

Setelah itu mereka bersyukur kepada Yang Maha Kuasa karena telah mempersatukan mereka agar tetap aman dan rukun.

Kutipan di atas menyatakan bahwa mereka masih memiliki kepercayaan terhadap sang pencipta, agar selalu dilindungi dan aman tentram. Berbagai macam kepercayaan masyarakat yang berbeda-beda setiap individu, yang dapat kita pelajari dan kita terapkan dalam kehidupan kita. Kepercayaan manusia terhadap adanya Sang Maha pencipta yang muncul kerena adanya kesadaran manusia itu sendiri.

\section{Sistem Ilmu dan Pengetahuan}

Pengetahuan adalah segala sesuatu yang diketahui manusia tentang benda, sifat, keadaan, dan harapan-harapan. Mereka memperoleh pengetahuan melalui pengelaman, intuisi, wahyu, dan berpikir menurut logika, atau percobaan yang bersifat empiris. Ilmu pengetahuan mempunyai peran penting dalam aktivitas beripikir manusia. Sistem pengetahuan ini tergambar dalam cerita rakyat Buah Udak, yaitu sebagai berikut:

Jadi, anaknya terus menanggis "mengapa kamu menanggis bah abang, makan sudah makan" kata si Mia Udak kepada anaknya. Sedangkan Kolin bekerja sebagai penepuh segala pisau, parang, dan lainlainya yang bisa untuk dijualkan.

Kutipan di atas menjelaskan
bahwa adanya
pengetahuannya jual beli barang
yang akan ditukar. Yang biasa
dilakukan oleh pedagang menjadi
salah satu ilmu pengetahuan yang
mereka dapatkan dalam hal
berdagang atau menjual barang
lainnya. Pengetahuan ini turun
temurun pada generasi penerus.

\section{PENUTUP}

Berdasarkan hasil dari analisis pada nilai dan unsur budaya pada cerita rakyat suku dayak Linoh pada cerita rakyat Buah Udak terdapat 5 (lima) nilai budaya yang terdiri dari: 1) nilai 
budaya dalam hubungan manusia dengan Tuhan. 2) nilai budaya dalam hubungan manusia dengan alam, 3) nilai budaya dalam hubungan manusia dengan masyarakat, 4) nilai budaya dalam hubungan manusia dengan orang lain atau sesamanya, 5)nilai budaya dalam hubungan manusia dengan dirinya sendiri.

Unsur budaya yang terdapat pada penelitian ini yakni 6 (enam) unsur budaya: 1) peralatan dan perlengkapan hidup (teknologi), 2) sistem kekerabatan dan organisasi social, 3) bahasa, 4) kesenian, 5) sistem kepercayaan (religi), 6) sistem ilmu dan pengetahuan.

\section{DAFTAR PUSTAKA}

Choirudin, M. (2018). Nilai Budaya Dalam Buku Cerita Rakyat Paser Dan Berau. Jurnal Basataka, Vol. 1, No. 1, Hal. 45-57.

Gumilar, S., \& Sulasman. (2013). Teori-Teori Kebudayaan. Bandung: Pustaka Setia.

Hutomo, S. S. (1991). Pengantar Studi Sastra Lisan. Surabaya: HISKI Komisariat Jawa Timur.

Indrastuti, N. S. (2018). Representasi Unsur Budaya dalam Cerita Rakyat Indonesia: Kajian Terhadap Status Sosial dan Kebudayaan Masyarakat. Malaysian Journal of Social
Sciences and Humanities (MJSSH), Volume 3, Issue 3, (page 189-199).

Koentjaraningrat. (1994). Pengantar Ilmu Antropologi. Jakarta: Rineka Cipta.

Liliweri, A. (2014). Pengantar Studi Kebudayaan. Bandung: Nusa Media.

Putri, N. S., \& Nugraha, O. A. (2017). Perbandingan Struktur, Fungsi, dan Nilai Budaya Pada Legenda Telaga Ngebel Ponorogo dan Legenda Danau Ranu Pasuruan. Jurnal Pena Indonesia, Vol. 3 No. 2 Hal. 201-222.

Sahril. (2013). Nilai Budaya dan Pendidikan Karakter Dalam Cerita Rakyat Sumatera Utara: Suatu Kajian Model SKEMA Aktan dan Skema Fungsi Greimas. Madah (Jurnal Ilmiah Bahasa dan Sastra), Vol. 4, No. 2, Hal. 208-225.

Sugiyono. (2015). Metode Penelitian Kuantitatif Kualitatif dan $R \& D$. Bandung: Alfabeta.

Zakiyah, Q. Y., \& Rusdiana. (2014). Pendidikan Nilai: Kajian Teori dan Praktik di Sekolah. Bandung: Pustaka Setia. 